\section{Endoscopic Insertion of an M2A Video Capsule through an Overtube}

The M2A video capsule (Given Imaging Ltd., Yoqneam, Israel) is slightly larger than large antibiotic tablets. Some patients have difficulties in swallowing the capsule, not only due to its size but also because of emotional aspects. We report here the case of a 74-year-old man with gastrointestinal bleeding in the context of acquired idiopathic von Willebrand disease. The source could not be located with upper and lower gastrointestinal endoscopy. As he had a long-standing aversion to any form of oral medication, the patient was unable to swallow the M2A capsule.

It was therefore decided to insert the capsule endoscopically. Initial ex vivo attempts to grip the capsule showed that neither a polypectomy snare, nor Dormia baskets of different sizes, nor polyp retrievers were able to fix the capsule securely. An overtube (Olympus, Hamburg, Germany) was therefore inserted over a video gastroscope, with the patient under conscious sedation. The capsule was then introduced into the overtube and pushed into the stomach endoscopically. Capsule endoscopy was completed successfully and revealed actively bleeding angiodysplasias in the proximal jejunum, which were subsequently controlled with argon plasma coagulation using a push enteroscope.

Video capsule endoscopy is a valuable technique in the work-up of small-bowel bleeding [1]. However, some patients are unable to swallow the capsule. It has been reported previously that the capsule can be grasped with a polypectomy snare and transferred endoscopically into the stomach or duodenum [2-4]. However, this approach seems unsafe for passage of the upper esophageal sphincter, as the capsule can easily slip out of the snare, especially in the vertical position needed to pass the sphincter. Slippage might in fact lead to aspiration; a case of capsule aspiration in another setting was recently reported [5]. By contrast, pushing the capsule through an overtube is a safe method

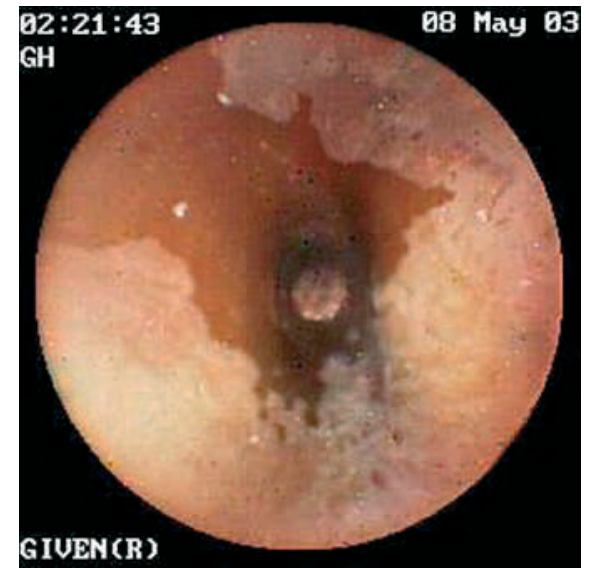

Corresponding Author

W. Mohl, M.D.

Dept. of Internal Medicine/

Gastroenterology

Caritas Hospital St. Theresia

Rheinstraße. 2

66113 Saarbrucken

Germany

Fax: $\quad$ +49-681-406-1003

E-mail: w.mohl@caritasklinik.de
Figure 1 View of the passage of the M2A capsule through the overtube. Note the reddish appearance in the proximal areas, where the overtube is clinging to the lower pharyngeal wall.

that allows full visual control of correct capsule placement.

\section{W. Mohl, A. Schneider, M. P. Lutz}

Dept. of Internal Medicine/Gastroenterology, Caritasklinik St. Theresia, Saarbrucken, Germany.

\section{References}

${ }^{1}$ Firemann Z, Kopelman Y. The role of video capsule endoscopy in the evaluation of iron deficiency anaemia. Dig Liver Dis 2004; 36: $97-102$

${ }^{2}$ Aabakken I, Scholz T, Ostensen ABet al. Capsule endoscopy is feasible in small children. Endoscopy 2003; 35: 798

${ }^{3}$ Aabakken I, Blomhoff JP, Jermstad T, Lynge AB. Capsule endoscopy in a patient with Zenker's diverticulum. Endoscopy 2003; 35: 799

${ }^{4}$ Hollerbach S, Kraus K, Willert Jet al. Endoscopically assisted video capsule endoscopy of the small bowel in patients with functional gastric outlet obstruction. Endoscopy 2003; 35: 226-229

${ }^{5}$ Schneider ARJ, Hoepffner N, Rösch W, Caspary WF. Aspiration of an M2A capsule. Endoscopy 2003; 35: 713 